medRxiv preprint doi: https://doi.org/10.1101/2020.11.17.20210211; this version posted November 18, 2020. The copyright holder for this preprint (which was not certified by peer review) is the author/funder, who has granted medRxiv a license to display the preprint in perpetuity. It is made available under a CC-BY 4.0 International license .

\title{
The impacts of COVID-19 mitigation on dengue virus transmission: a modelling study
}

Sean M Cavany ${ }^{1}$, Guido España ${ }^{1}$, Gonzalo M Vazquez-Prokopec ${ }^{2}$, Thomas W Scott ${ }^{3}$, T Alex Perkins ${ }^{1}$

1. Department of Biological Sciences, University of Notre Dame

2. Department of Environmental Sciences, Emory University

3. Department of Entomology and Nematology, University of California, Davis

Correspondence: scavany@nd.edu (Sean M Cavany); taperkins@nd.edu (T Alex Perkins) 


\section{Summary}

Background The COVID-19 pandemic has induced unprecedented reductions in human mobility and social contacts throughout the world. Because dengue virus (DENV) transmission is strongly driven by human mobility, behavioral changes associated with the pandemic have been hypothesized to impact dengue incidence. By discouraging human contact, COVID-19 control measures have also disrupted dengue vector control interventions, the most effective of which require entry into homes.

Methods We used an agent-based model with a realistic treatment of human mobility and vector control to investigate how and why dengue incidence could differ under a lockdown scenario with a proportion of the population sheltered at home.

Results We found that a lockdown in which $70 \%$ of the population sheltered at home led to a small average increase in cumulative DENV infections of up to $10 \%$, depending on the time of year lockdown occurred. Lockdown had a more pronounced effect on the spatial distribution of DENV infections, with higher incidence under lockdown in regions with high mosquito abundance. Transmission was also more focused in homes following lockdown. The proportion of people infected in their own home rose from 54\% under normal conditions to $66 \%$ under lockdown, and the household secondary attack rate rose from 0.109 to 0.128 , a $17 \%$ increase. When we considered that lockdown measures could disrupt regular, city-wide vector control campaigns, the increase in incidence was more pronounced than with lockdown alone, especially if lockdown occurred at the optimal time for vector control.

Discussion Our results indicate that an unintended outcome of COVID-19 control measures may be to adversely alter the epidemiology of dengue. This observation has important implications for an improved understanding of dengue epidemiology and effective application of dengue vector control. When coordinating public health responses during a syndemic, it is important to monitor multiple infections and understand that an intervention against one disease may exacerbate another. 


\section{Introduction}

Public health measures taken to address the COVID-19 pandemic have had unprecedented effects on the lives of people around the world. While measures such as social distancing and stay-at-home orders have been successful in reducing transmission, morbidity, and mortality associated with SARS-CoV-2, they are likely to have also had an effect on the incidence of other diseases $(1,2)$. For example, lockdown measures are predicted to increase the burden of tuberculosis by reducing care-seeking behavior and to increase the burden of HIV due to disruption of antiretroviral therapy $(3,4)$.

Dengue is a mosquito-borne viral disease endemic across much of the tropics, with an estimated 400 million infections and 40,000 deaths each year $(5,6)$. A number of countries with particularly severe COVID-19 epidemics regularly experience dengue epidemics (e.g., Peru, Brazil, and Indonesia), and there have been reports of 2020 being an above-average year for dengue in South America (7). A number of warnings have been raised regarding the potential dangers of overlapping dengue and COVID-19 epidemics; e.g., both diseases can result in similar symptoms and there have been reports of serological cross-reaction, which increases the chance of misdiagnosis (8-14). At least five cases of dengue-COVID-19 co-infection have been reported, one of which resulted in death by stroke $(9,14-$ 18). Most concerningly, other researchers have raised concerns about the possible impact of interrupted vector control campaigns and called for efforts to overcome this adverse impact $(19,20)$.

Dengue virus (DENV) transmission is influenced by multiple overlapping drivers, including human and mosquito movement; climate and environmental factors that affect mosquito abundance, contact with human hosts, and vector-virus interactions; human host immunity; and virus genotype (21-26). Hence, predicting the epidemiological impact of drastic changes in human mobility on DENV transmission is difficult because of the large number of potentially influential variables that interact in complex ways. It is understood that daily routine movement between houses is a key driver of DENV transmission, and it is this type of movement that has been most affected by lockdown measures (24). While reductions in these house-to-house movements could be expected to reduce transmission, it may also be the case that increased opportunities for intra-household transmission coupled with local mosquito movement and imperfect compliance with lockdown could heighten transmission. Hence, it is unclear in which direction transmission should change in response to lockdown.

We used an established, agent-based model of DENV transmission (27) to explore the impact of lockdown on dengue incidence. Our model incorporates a detailed, realistic, and spatially explicit representation of human mobility and spatiotemporal patterns of mosquito abundance. It is calibrated to dengue incidence in the city of Iquitos, Peru, and has been previously used to answer a number of questions of public health significance beyond that specific setting $(28,29)$. In this study, we compared the effects of initiating lockdown in different DENV transmission seasons and at different times within a transmission season. We focused on lockdown effects on (1) the incidence and spatial distribution of DENV infections, (2) local transmission by calculating household secondary attack rates, and (3) disrupted vector control campaigns. As a whole, this analysis yields predictions about how lockdown could affect dengue and the mechanisms by which it could do so.

\section{Results}

\section{Effect of lockdown timing on dengue incidence}

Our model is calibrated to data from an 11-year time period (27). We therefore focused our analysis on 
medRxiv preprint doi: https://doi.org/10.1101/2020.11.17.20210211; this version posted November 18, 2020. The copyright holder for this preprint (which was not certified by peer review) is the author/funder, who has granted medRxiv a license to display the preprint in perpetuity.

It is made available under a CC-BY 4.0 International license .

three scenarios corresponding to representative transmission seasons: one with low incidence (2004-05, "low" hereafter), one with high incidence but no new serotype invasion (2000-01, "high" hereafter), and one with high incidence due to a new serotype invasion (2001-02, invasion of DENV-3, "serotype invasion" hereafter) (Figure 1). In each of these scenarios, we initiated lockdown on the first of each month to explore the effect of initiating lockdown at different times of year. The effect of the month in which lockdown was initiated varied across scenarios (Figure 2, Supplementary Figures 1-3). In the low and high scenarios, lockdown had little effect on the incidence of DENV infection; i.e. the timing of lockdown was not important (Figure 2). In the serotype invasion scenario, the timing of lockdown was much more important. Initiating lockdown early in the season (July - October) led to similar local incidence as the no-lockdown scenario (e.g., initiating in July led to 130,434 infections (95\% uncertainty interval (UI): 122,674 - 150,995), a 0.2\% decrease) (Figure 3, Supplementary Figure 4). Conversely, initiating lockdown just after the seasonal peak in infections (June) led to many more infections (e.g., 144,668 infections (95\% UI: 136,812 - 162,403), an 11\% increase). This part of the season follows the period of highest incidence, and so is when prevalence and the force of infection are at their highest.

High Sero. inv. Low

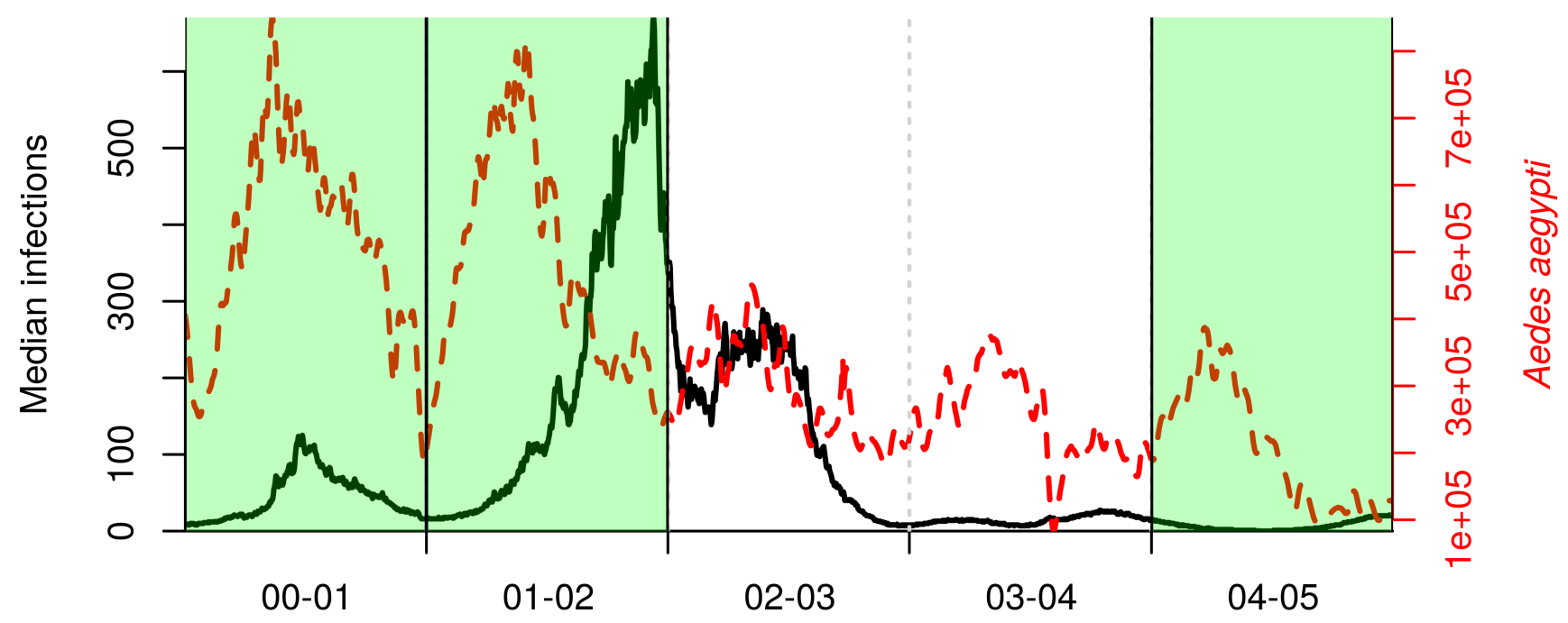

Season

Figure 1: Median incidence of DENV infections (black solid line) and total mosquito abundance (dashed red line) in our reconstruction of dengue virus transmission during 2000-2005 in Iquitos. Vertical dashed lines delineate transmission seasons, defined as beginning on July 1. Highlighted in green are three seasons in which we initiated lockdown, chosen to represent a range of possible epidemiological scenarios. 

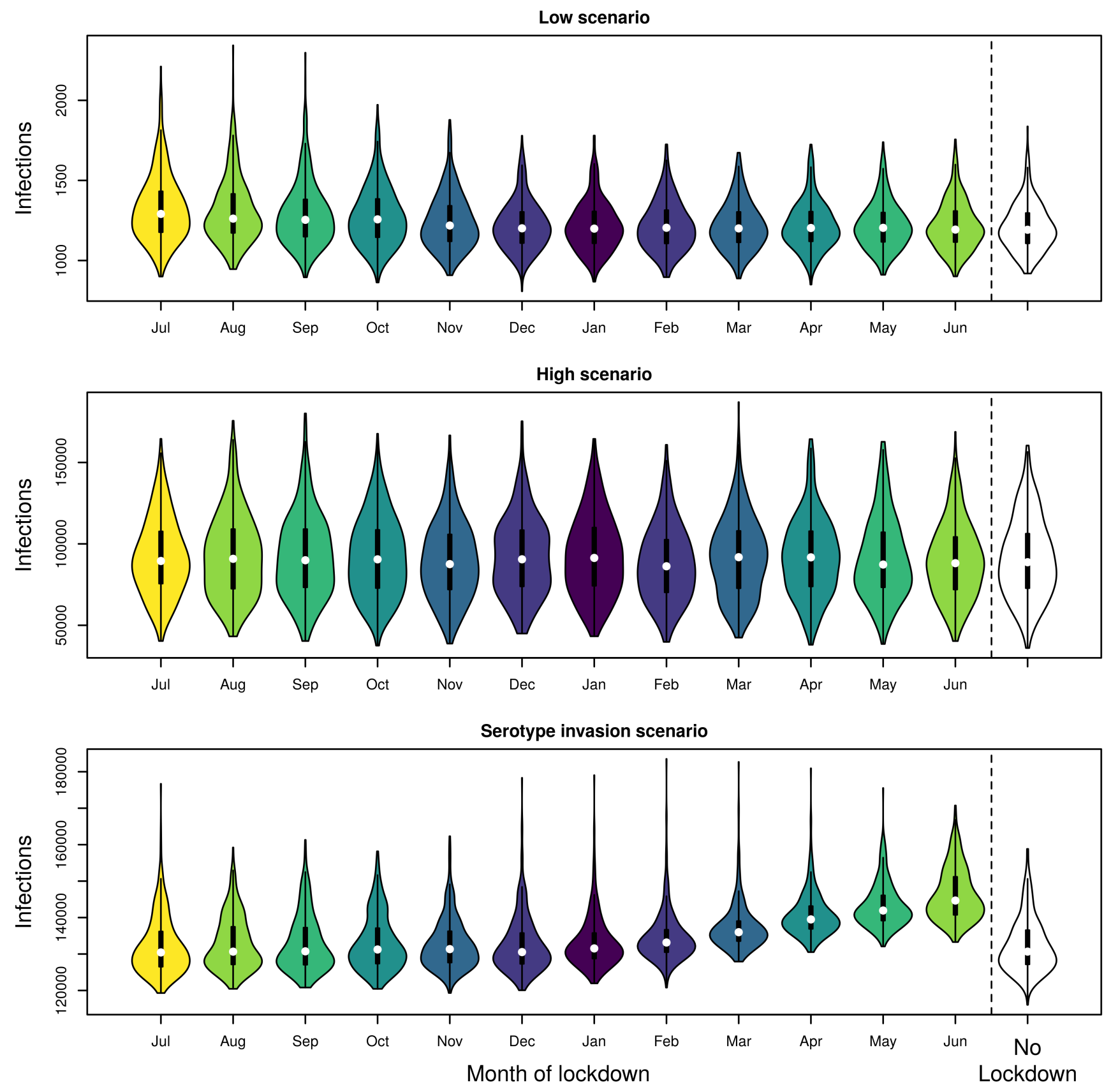

Figure 2: Comparison of cumulative DENV infections when lockdown started on the first of the month in the shown month. Incidence was summed over both the season in which lockdown was initiated and the following season.

\section{Spatial and locational effects of lockdown}

When we initiated a three-month lockdown in mid-March in the serotype invasion scenario, lockdown changed the spatial distribution of infections (Figure 3). Mid-March was chosen because that is when COVID-19 mobility restrictions were put in place in 2020, and because we observed a moderate effect of lockdown initiated in March in the serotype invasion scenario (Figure 2). In 20/35 Ministry of Health zones, infections rose, with the greatest increases in the northeast and southwest of the city. Notably, the zones with the greatest increases were those zones with the highest average Ae. aegypti 
medRxiv preprint doi: https://doi.org/10.1101/2020.11.17.20210211; this version posted November 18, 2020. The copyright holder for this preprint (which was not certified by peer review) is the author/funder, who has granted medRxiv a license to display the preprint in perpetuity.

It is made available under a CC-BY 4.0 International license .

abundance. Those with a decrease had the lowest average Ae. aegypti abundance (Pearson's correlation, $r=0.946)$. The correlation between cumulative incidence and average mosquito abundance was $r=0.925$ when no lockdown occurred, compared to $r=0.946$ with lockdown. This indicates that spatial abundance of mosquitoes becomes a stronger determinant of dengue incidence when human mobility is reduced. Neither human population density $(r=-0.344)$ nor changes in the total number of person-days spent in each zone $(r=0.056)$ were strongly correlated with changes in incidence.

While some zones where people spend more time under lockdown were those where there was also greater mosquito abundance (e.g., in the northeast), other zones with high mosquito abundance saw reductions in the amount of time spent there (e.g., in the southwest) (Figure 3B and D). Notably, these southwest zones saw increases in incidence despite, in most cases, fewer person-days being spent there (Figure 3A and D). This indicates that the effect of the spatial distribution of mosquitoes outweighs the effect of changes in the parts of the city where people spend their time during lockdown. 
medRxiv preprint doi: https://doi.org/10.1101/2020.11.17.20210211; this version posted November 18, 2020. The copyright holder for this preprint (which was not certified by peer review) is the author/funder, who has granted medRxiv a license to display the preprint in perpetuity.

It is made available under a CC-BY 4.0 International license .

A. Difference in incidence

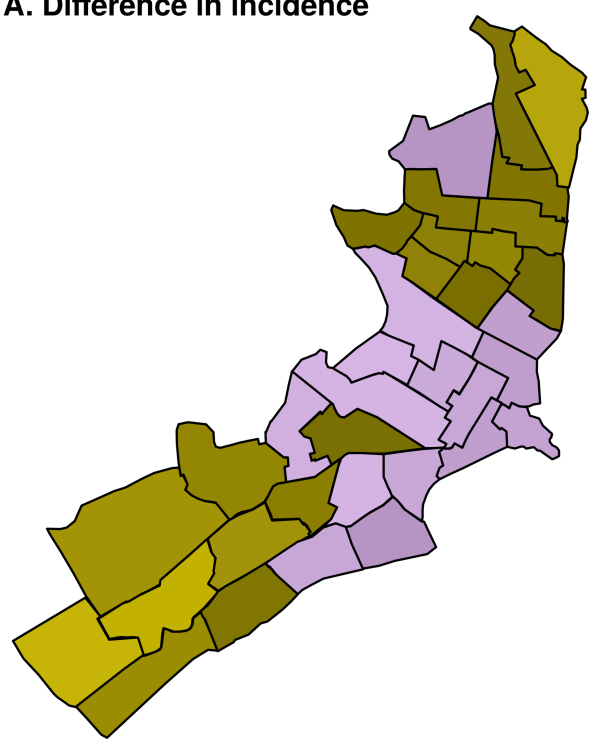

C. Population density $/ \mathrm{km}^{2}$

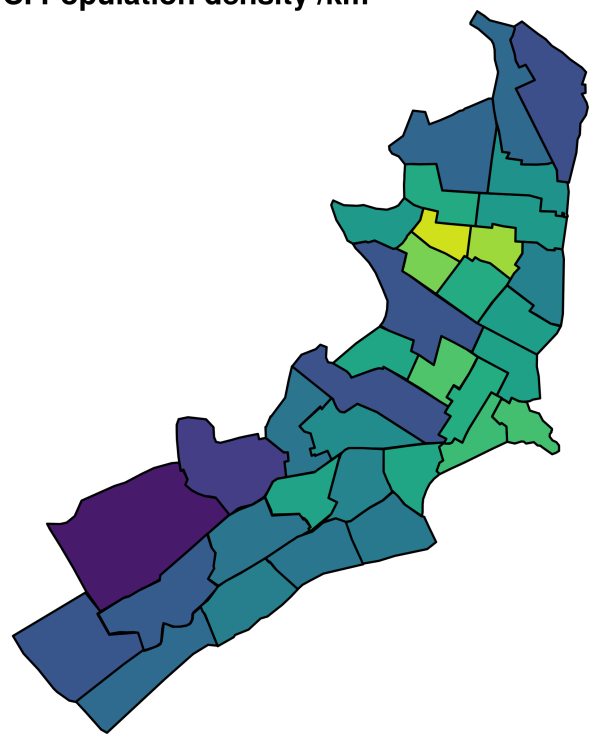

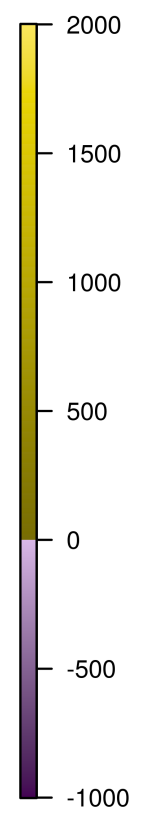

B. Average mosquito abundance

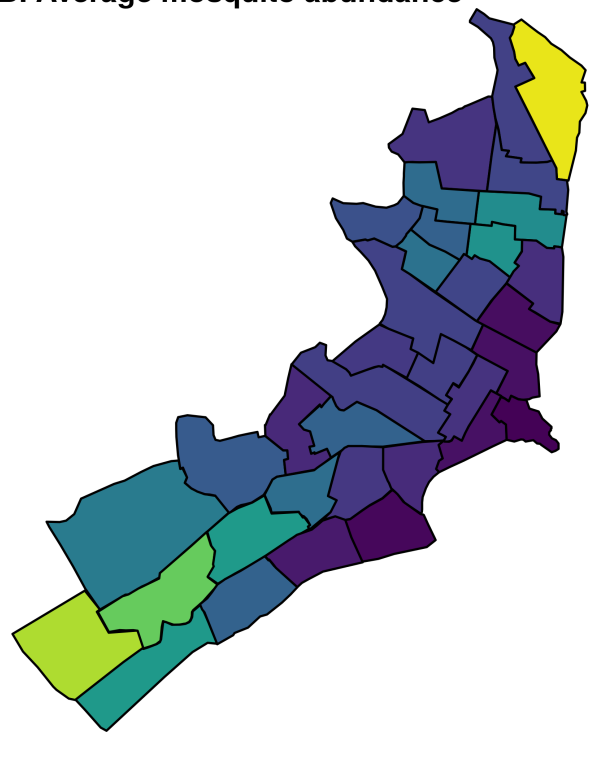

D. Difference in total person-days

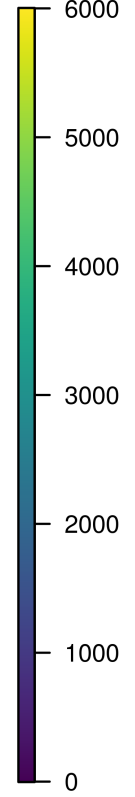

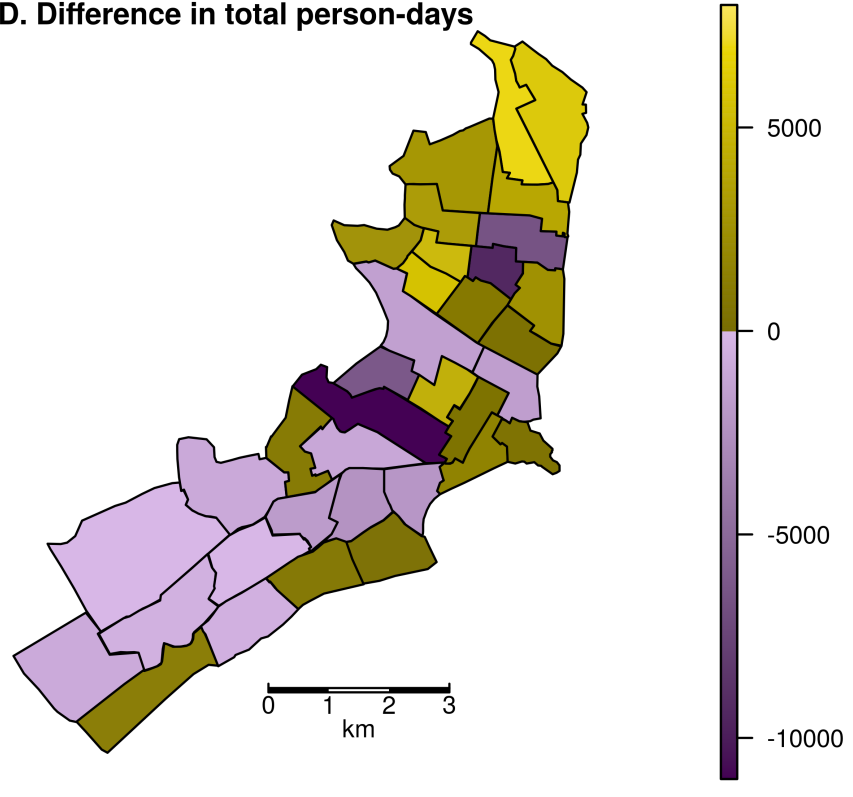

Figure 3: Map of Iquitos, with the 35 Ministry of Health $(\mathrm{MoH})$ zones delineated. In panels A and $D$, yellow indicates increases and blue indicates decreases. A: Spatial distribution of changes in total incident DENV infections across a two-year period including the serotype invasion and following seasons. Lockdown was initiated on March 17 in the serotype invasion season. B: Total mosquito abundance across different $\mathrm{MoH}$ zones, averaged across the two-year period. C: Population density of the $\mathrm{MoH}$ zones. D: Difference in the total person-days spent in each zone between lockdown and baseline scenarios assuming 70\% of people comply with lockdown measures.

The type of location where infections took place noticeably changed under lockdown. In the baseline scenario, 54.5\% (95\% UI: 54.3\% - 55.0\%) of infections occurred in the home of the infected individual. In contrast, when a lockdown occurred in mid-March in the serotype invasion season, 
$66.3 \%$ (95\% UI: $58.9 \%$ - 70.2\%) of infections occurred in the infected person's home. This had an effect on the household secondary attack rate, which increased from a mean of 0.109 (95\% UI: 0.0999, 0.126 ) in the baseline scenario to 0.128 (95\% UI: $0.119,0.146$ ) in the lockdown scenario, a $17 \%$ increase. In our model, lockdown had a negligible impact on the total number of mosquito bites on humans because the time when mosquitoes take blood-meals is determined by the temperature-driven gonotrophic cycle period, not the number of humans present.

\section{Changing distributions of people and blood-meals}

According to the most recent available information, there are 92,896 buildings in Iquitos. Comparing typical patterns of human mobility in Iquitos with those under lockdown (assuming each person spends more time at home), we would expect 78,562 (85\%) buildings to have more people inside them during lockdown. Every location that was expected to have more people under lockdown was a residential location, while all non-residential locations had fewer people, on average, under lockdown. There were 9,761 residential locations ( $11 \%$ of all residential locations) that had a higher average number of people under lockdown. Under lockdown, the number of unique visitors per location increased in just 105 locations (0.11\%) and decreased in 87,276 locations (94\%).

Model simulations showed that the number of unique individuals bitten by a single mosquito increased under lockdown. In the serotype invasion scenario with a three month lockdown beginning in mid-March, the number of unique individuals each mosquito bit in its lifetime rose from 2.54 to 2.64 (3.9\%). In all three scenarios, the number of unique bites rose by $0.09-0.10$ bites. This increase in the number of unique bites was due to heterogeneity in the number of people per location. In the baseline scenario, the Gini coefficient of the number of people in each house was 0.635 , whereas under lockdown it was 0.402. As a smaller Gini coefficient implies greater homogeneity, this suggests that the number of people per house was more homogeneous under lockdown. In turn, this implies that in the baseline scenario there was more heterogeneity in the number of unique individuals available for each mosquito to bite, resulting in fewer bites on unique individuals on average.

\section{Importance of vector control}

In addition to the effects of lockdown on incidence caused by changes in mosquito-human encounters, lockdown can affect incidence by disrupting vector control. If an early-season vector-control campaign (July or August) was interrupted by public health measures against COVID-19, the impact of lockdown and the interrupted campaign was small, but still more than double the incidence of infection immediately following lockdown (Figure 4, Supplementary Figure 4, Jul and Aug panels). If the lockdown instead took place just prior to the seasonal peak (e.g., March), this led to a large increase in the size of the epidemic by a factor of greater than 10 at the peak of the season (Figure 4, Supplementary Figure 4, Mar panels). In the alternative scenario in which vector control proceeded as planned during lockdown, there was a large rebound in infections the following season, due to low population immunity. That rebound could be mitigated partially by a delayed campaign following lockdown, or a city-wide campaign in the subsequent year (Supplementary Figures 5-7). 
medRxiv preprint doi: https://doi.org/10.1101/2020.11.17.20210211; this version posted November 18, 2020. The copyright holder for this preprint (which was not certified by peer review) is the author/funder, who has granted medRxiv a license to display the preprint in perpetuity.

It is made available under a CC-BY 4.0 International license .
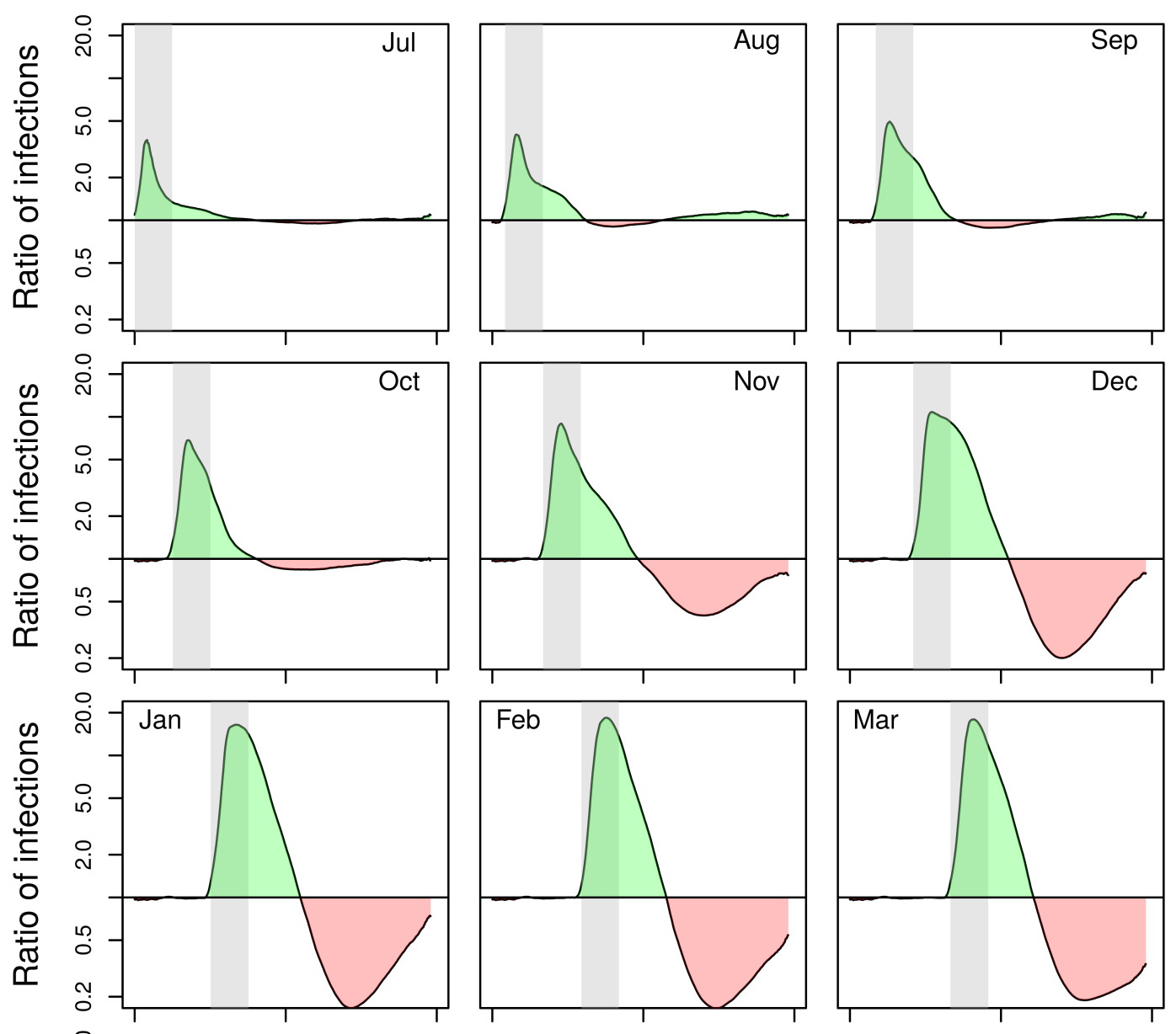

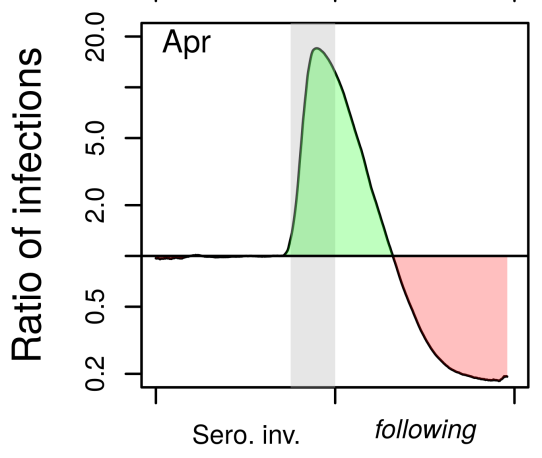

Season

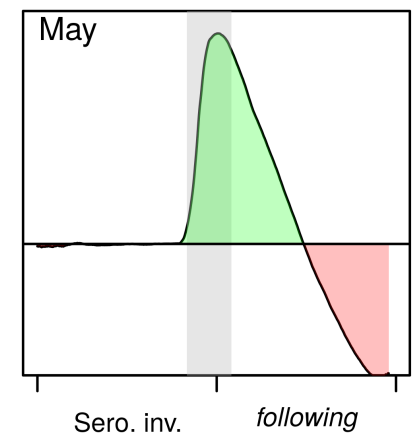

Season

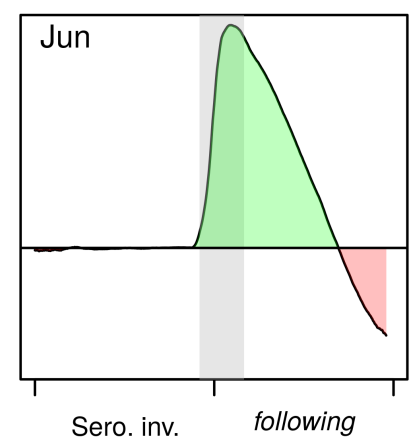

Season

Figure 4: Ratio of the mean number of infections under lockdown without vector control to the mean number in the baseline scenario without lockdown but with vector control. Results are for the serotype invasion and following season, when lockdown is initiated in different months (shown in the top corner of the panel). When lockdown did not occur, there was a city-wide vector control campaign, but this was interrupted in the lockdown scenario. Lockdown/vector control occurred during the gray band. Green shading indicates an increase in infections under lockdown without vector control, whereas red shading indicates a decrease.

\section{Sensitivity analysis}

In all baseline analyses, we used values of 70\% compliance with lockdown orders and a lockdown 
length of three months. We explored changing these values in a one-at-a-time sensitivity analysis in the serotype invasion season beginning lockdown in mid-March (Supplementary Figures 8 and 9). Compliance had a non-linear, non-monotonic relationship with the cumulative number of infections (Supplementary Figure 8). The cumulative number of infections peaked at slightly below 90\% compliance. This indicates that while lockdown tends to increase DENV incidence, the optimal conditions for transmission require some amount of human mobility. Even if compliance were 100\%, however, our results indicate that incidence would still rise compared to typical movement patterns. Longer lockdowns appeared to increase cumulative DENV incidence, though this effect saturated at around 150 days (Supplementary Figure 9).

Because human mobility was severely curtailed during lockdown and mosquito distribution patterns were correlated with changes in DENV incidence, the role of mosquito movement in transmission may have been heightened in our model. We explored this by varying the daily probability of mosquito movement in simulations with and without lockdown (Figure 5). Irrespective of whether lockdown occurred, incidence peaked when the daily probability of mosquitoes moving from a house was around 0.2. Regardless of lockdown, there was no transmission when mosquitoes did not move between houses, because house-level mosquito extinctions could not be replenished. As mosquito movement increased, so did the proportional change in the number of infections in lockdown compared to no lockdown (Figure 5B). This indicates that the role of mosquito movement is heightened under lockdown. If its role were the same in both situations, we would expect this ratio to remain at 1 across the range of mosquito movement probabilities.

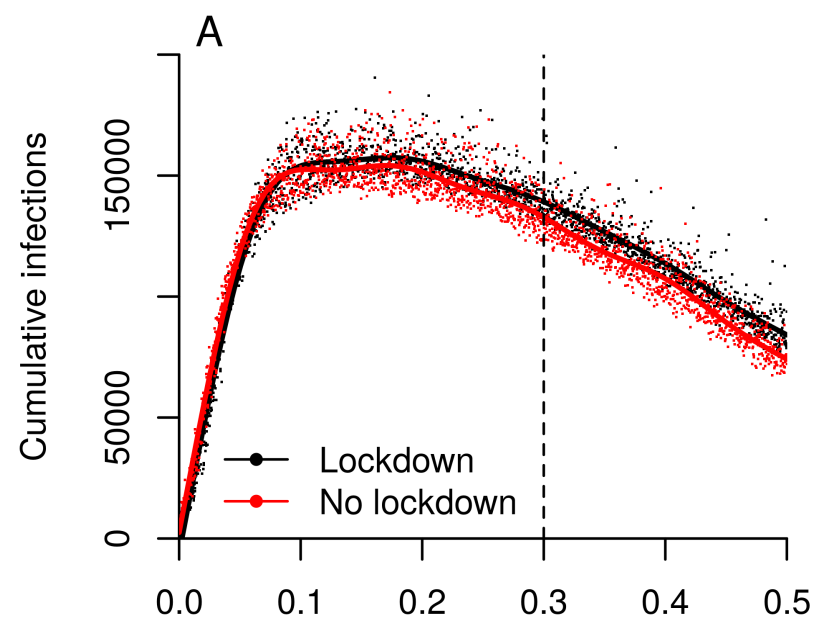

Daily mosquito move probability

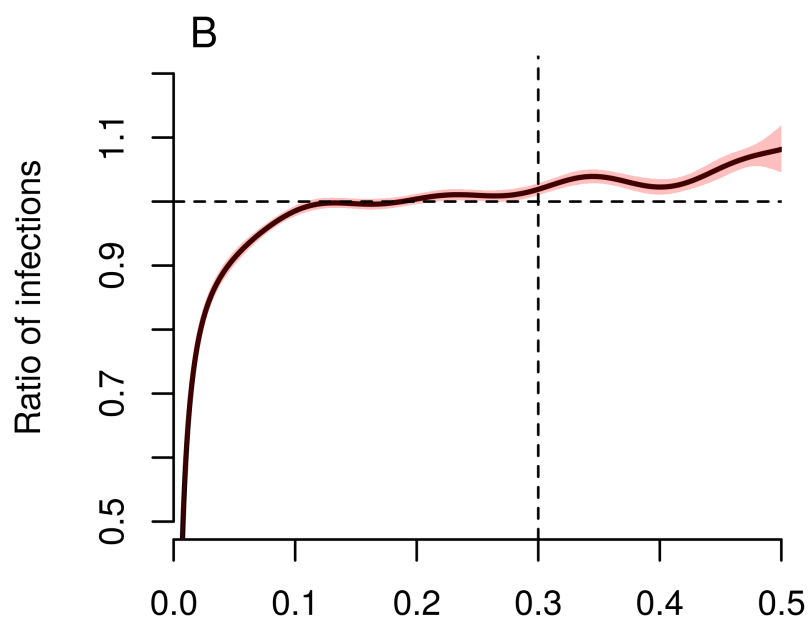

Daily mosquito move probability

Figure 5: Role of mosquito movement. A. Cumulative infections for different values of daily mosquito movement probability, with and without lockdown. The dashed vertical line indicates the default value (0.3) that was used in all other simulations. B. The ratio of the average number of infections in $a$ lockdown scenario to the number without lockdown. The dashed horizontal line represents when these two situations are the same. If the solid line is above the dashed horizontal line, lockdown resulted in more cumulative infections than when there was no lockdown. The dashed vertical line indicates the default value that was used in all other simulations. 


\section{Discussion}

We found that lockdown movement restrictions led to an increase in DENV transmission in our model. Though the increase was relatively modest, the effect was more pronounced when lockdown occurred toward the end of the transmission season, the period of time when prevalence is typically at its highest following several months of transmission. Lockdown had a more pronounced effect in changing the locations where transmission occurred and the spatial distribution of infections. Specifically, more infections occurred in people's homes than at other types of locations, which increased the household secondary attack rate by $17 \%$. This meant that more infections occurred where mosquito abundance was highest, amplifying hyperlocal transmission due to incomplete compliance with lockdown and mosquito movement among nearby houses. Overall, transmission rose under lockdown mainly because of a concentration of transmission in areas with high mosquito abundance and because of an increase in the number of unique people that a single mosquito took blood-meals from in its lifetime. When we considered the effect of potential interruptions to vector control, lockdown led to much greater increases in DENV transmission.

Our results identified three factors contributing to the direct effect of lockdown on DENV transmission apart from interruption of vector control. First, lockdown causes infections to become more concentrated in locations where mosquito abundance is highest, facilitating more transmission than might occur otherwise. Second, people spending more time at home causes an increase in the household secondary attack rate. Under non-lockdown circumstances, uninfected household members spend more time outside the home and thereby reduce their exposure. Third, lockdown results in a more homogeneous distribution of person-hours across locations, which leads to an increase in the number of unique individuals that each mosquito bites. This increases the chance that a mosquito becomes infected within its lifetime, as well as the chance that a mosquito gets infected by one person and later infects a different person.

These direct effects of lockdown are likely to be greatest in settings where transmission predominantly occurs in homes and where household-level mosquito abundance is typically high. In Iquitos, this assumption is supported both by pupal surveys of Aedes aegypti mosquitoes in nonresidential locations (30) and epidemiological investigations of contact-site clusters $(24,31)$. Rather than to model the interaction between COVID-19 and dengue as it unfolded in Iquitos, however, our goal was to use a model previously developed for Iquitos to address a general question about the effect of lockdown on dengue. Even so, it is worth noting that Iquitos did experience a large COVID-19 epidemic beginning in March 2020, which severely strained health services there (32). Just before then, the city experienced a relatively large dengue epidemic in December 2019 through March 2020 (33). Extensive disruption of health services thereafter for illnesses other than COVID-19 makes it difficult to know what the course of that dengue epidemic was once COVID-19 came to the fore (32). Given how large the COVID-19 epidemic in Iquitos appears to have been (34), compliance with lockdown there may have been low. Although low compliance with lockdown would reduce the direct effects of lockdown on dengue that we demonstrated with our model, reductions to vector control services may have had effects on dengue that went unnoticed by surveillance and that could have implications for the next dengue season.

Globally, there have been reports of both rising $(8,35,36)$ and falling $(37)$ dengue incidence 
since the COVID-19 pandemic began. A study from Thailand was able to associate increases in dengue incidence there with interventions against COVID-19 (38), consistent with our findings. The observational nature of that study did not allow for the mechanisms behind that association to be understood, but the authors hypothesized that it may have been due to heightened exposure to vectors while people spent more time in their homes (38). Our analysis adds value by testing that hypothesis through simulation experiments and elucidating how the strength of those effects is modulated by other factors, such as spatial heterogeneity in mosquito abundance, the spatial scale of mosquito movement, compliance with lockdown, and the seasonal timing of lockdown. Another factor that could be important in modulating effects of lockdown on dengue is the extent to which DENV transmission occurs at other types of locations, such as schools $(39,40)$. In settings where schools or other nonresidential locations are important for DENV transmission, lockdown measures could have a qualitatively different effect by reducing the number of people in those high-risk locations. Nonetheless, homes and their vicinity remain a key site of transmission in many settings, and we expect that our finding that lockdown further increases transmission in such locations will be robust (41-46).

The scale of the non-pharmaceutical interventions undertaken to combat the COVID-19 epidemic have likely impacted a number of other diseases, either directly or indirectly. Some of these effects may be positive. For instance, due to the shared route of transmission, interventions against COVID-19 impact influenza in a similar way, and likely contributed to very low flu seasons during the Southern Hemisphere winter (47). On the other hand, disruption of key services and reductions in careseeking behavior are projected to have negative effects on the burden of TB, malaria, HIV/AIDS, and a range of vaccine-preventable diseases $(3,4,48-51)$. Our results align more closely with the latter pattern, showing a potentially large negative effect if dengue vector control campaigns are interrupted. To mitigate this, public health authorities could encourage or assist people to spray their own homes, by providing them with self-use insecticide treatments (52).

A significant strength of our study is our spatially explicit treatment of human mobility, which allowed us to isolate the effect of lockdown in ways that a simpler model could not. Moreover, our model's direct inclusion of mosquito movement and individual biting behaviour allowed us to understand the changing role of these factors in DENV transmission when movement restrictions were imposed. Our study also has at least three limitations. First, it is difficult to know the exact response people made to lockdown measures, such as the level of compliance and how the nature of their movements changed. Our sensitivity analysis of lockdown compliance and duration found that reduced compliance linearly decreased the change in incidence due to lockdown. Second, we assumed that mosquito behavior was unaffected by changes in human mobility. It has been suggested that there may be an increase in larval habitats due to lockdown measures; e.g., if unattended workplaces means that larval development sites increase (53). Third, we did not assess impact in terms of severe disease; e.g., dengue hemorrhagic fever (DHF). We made this decision because of severe dengue's dependence on the local immunity profile and circulating serotype, which would mean DHF results would be difficult to generalize. Our model was also calibrated to a statistical reconstruction of incidence of infection (26) rather than disease. Nonetheless, increased incidence of DENV infection would, all else being equal, be expected to translate to higher rates of DHF; a very concerning situation in the context of already strained health systems due to COVID-19.

Our findings illustrate why, during a syndemic, public health officials must consider the 
implications of an action to prevent one disease on other concurrent diseases (54). Thus, a holistic approach to infectious disease mitigation is needed. Research and policy efforts should focus on ways to retain the positive effects of lockdown on diseases like COVID-19, influenza, and pneumonia while mitigating the negative effects on dengue, malaria, and TB. Whenever there is risk of DENV transmission, efforts must be made to avoid disrupting vector control and provide carefully planned alternative means of making vector control possible. More creativity may be needed to ensure the continuation of vector control than to rely solely on providing vector control staff with personal protective equipment to carry out existing forms of control (19).

\section{Methods}

\section{Model overview}

A detailed explanation of all features of the model is given in the Supplementary Text and previous publications (27-29,55). In brief, we used an established agent-based model of DENV transmission (27), with a detailed and realistic model of human movement (56), to explore how preventive measures taken against COVID-19 could affect DENV transmission. Our model is based on the city of Iquitos, in the Peruvian Amazon. Human agents in the model move around the city according to individualized movement trajectories, calibrated to data on movement patterns in Iquitos from semi-structured interviews with residents (56). The average distribution of mosquito agents in the model follows spatiotemporal estimates of abundance based on household surveys (57). Mosquito agents also move, but much less than human agents. Each mosquito determines when to bite based on a temperature dependent rate parameter, and who to bite based on the body sizes of humans present at that time. Transmission occurs between mosquito and human agents when one agent (either mosquito or human) is susceptible and the other infectious, a blood-meal is taken by the mosquito, and the infection establishes in the susceptible agent, which occurs with a fixed probability. Transmission in the model is partially driven by time series of imported infections, which were calibrated to estimates of the timevarying, serotype-specific force of infection $(26,27)$.

\section{Simulations}

To understand the impact that lockdown could have on dengue, we simulated historical transmission under typical movement patterns and those that might be expected under lockdown. We defined lockdown as $70 \%$ of the population staying at home instead of undertaking their typical movement trajectory for that day; e.g., individuals with non-essential jobs who comply with lockdown. We explored different values of compliance in a sensitivity analysis. We chose three representative seasons from the period 2000-10 that span a range of seasonal dynamics, including a high-transmission season (2000-01), a low-transmission season (2004-05), and a season involving invasion of a novel serotype (2001-02) (Figure 1). For our baseline setting, we simulated lockdowns lasting for three months, though we also explored different values of this timespan in a second sensitivity analysis. We explored starting lockdown in different months to understand how lockdown interplays with the seasonality of dengue. Except where stated otherwise, we started lockdown on March 17, which was the date lockdown began in 2020 in Peru. This showed a moderate effect in the serotype invasion season (Figure 2). We simulated vector control as a city-wide campaign in which all houses that complied (70\%) were sprayed three times in a three-week period; approximately 11,000 houses per day. The 
ultra-low volume treatment had no residuality and increased the mortality rate of mosquitoes in the household by 1.5 day $^{-1}$ on the day when spraying occurred $(28,58)$. We ran each simulation 400 times, as increasing the number of simulations past that point did not reduce the coefficient of variation in the number of DENV infections by more than $0.1 \%$ (59).

Analysis

For each scenario, we analyzed the distribution across simulations of the number of DENV infections in the transmission seasons including and immediately following the initiation of lockdown, and compared this to the same period in simulations without lockdown. We calculated the following outcomes:

1. The total number of infections through space and time,

2. The number of unique individuals each mosquito feeds on its lifetime, and

3. The average secondary attack rate by location, defined as the average proportion of household contacts infected in a season, excluding the first infection in the household.

In all figures except Figure 1, we show the incidence of local infections, because imported infections do not differ (on average) between simulations and excluding them makes differences more visible.

Without simulating the full model, we analyzed the effect of changing movement trajectories so that people spend more time at home. We quantified this impact by calculating the number of locations where:

1. The average number of people present was greater under lockdown and

2. The number of unique individuals that visit the house was greater under lockdown.

These outcomes are based purely on the modified activity spaces of individuals in the model, without directly simulating movement or transmission, and are presented in the "Changing distributions of people and blood-meals section.”

We undertook three sensitivity analyses: varying compliance, lockdown length, and mosquito movement probability. In all three cases, we swept across 2,000 parameter values, calculated the cumulative number of infections across two seasons, and fitted a generalized additive model (GAM) to the output using the mgcv package in $\mathrm{R}(60,61)$.

\section{Acknowledgements}

We thank Amy Morrison (University of California, Davis) for helpful discussion and commentary on the manuscript. We also thank the Proyecto Dengue team in Iquitos for performing research over many years that informed the development of our model. This research made extensive use of computing resources provided by the Center for Research Computing at the University of Notre Dame.

\section{Author contributions}

\section{Contributor Role}

Conceptualization

Study design

Data analysis

Data acquisition

\section{Contributors}

All authors

SMC, TAP

SMC

Not applicable 
medRxiv preprint doi: https://doi.org/10.1101/2020.11.17.20210211; this version posted November 18, 2020. The copyright holder for this preprint (which was not certified by peer review) is the author/funder, who has granted medRxiv a license to display the preprint in perpetuity. It is made available under a CC-BY 4.0 International license .

Data processing

Interpretation of data

Drafting of manuscript

Critical revision of manuscript

Final approval of manuscript

Laboratory procedures
Not applicable

All authors

SMC

All authors

All authors

Not applicable 


\section{References}

1. Flaxman S, Mishra S, Gandy A, Unwin HJT, Mellan TA, Coupland H, et al. Estimating the effects of non-pharmaceutical interventions on COVID-19 in Europe. Nature. 2020 Jun 8;

2. Lai S, Ruktanonchai NW, Zhou L, Prosper O, Luo W, Floyd JR, et al. Effect of nonpharmaceutical interventions to contain COVID-19 in China. Nature. 2020 May 4;

3. Hogan AB, Jewell BL, Sherrard-Smith E, Vesga JF, Watson OJ, Whittaker C, et al. Potential impact of the COVID-19 pandemic on HIV, tuberculosis, and malaria in low-income and middleincome countries: a modelling study. The Lancet Global Health [Internet]. 2020 Jul 13 [cited 2020 Jul 14];0(0). Available from: https://www.thelancet.com/journals/langlo/article/PIIS2214109X(20)30288-6/abstract

4. McQuaid CF, McCreesh N, Read JM, Sumner T, Houben RMGJ, White RG, et al. The potential impact of COVID-19-related disruption on tuberculosis burden. European Respiratory Journal [Internet]. 2020 Jan 1 [cited 2020 Jul 7]; Available from: https:/erj.ersjournals.com/content/early/ 2020/06/04/13993003.01718-2020

5. Bhatt S, Gething PW, Brady OJ, Messina JP, Farlow AW, Moyes CL, et al. The global distribution and burden of dengue. Nature. 2013 Apr;496(7446):504-7.

6. Stanaway JD, Shepard DS, Undurraga EA, Halasa YA, Coffeng LE, Brady OJ, et al. The global burden of dengue: an analysis from the Global Burden of Disease Study 2013. The Lancet Infectious Diseases. 2016 Jun 1;16(6):712-23.

7. Dengue in the Americas: 20 countries reporting higher-than-usual numbers prompting CDC travel notice [Internet]. Outbreak News Today. 2020 [cited 2020 Oct 5]. Available from: http://outbreaknewstoday.com/dengue-in-the-americas-20-countries-reporting-higher-than-usualnumbers-prompting-cdc-travel-notice-76746/

8. Cardona-Ospina JA, Arteaga-Livias K, Villamil-Gómez WE, Pérez-Díaz CE, Katterine BonillaAldana D, Mondragon-Cardona Á, et al. Dengue and COVID-19, overlapping epidemics? An Analysis from Colombia. J Med Virol. 2020 Jun 19;

9. Epelboin L, Blondé R, Nacher M, Combe P, Collet L. COVID-19 and dengue co-infection in a returning traveller. J Travel Med. 2020 Jul 13;

10. Haqqi A, Awan UA, Ali M, Saqib MAN, Ahmed H, Afzal MS. COVID-19 and dengue virus coepidemics in Pakistan: A dangerous combination for overburdened healthcare system. J Med Virol. 2020 Jun 8;

11. Miah MA, Husna A. Co-infection, co-epidemics of Covid-19 and Dengue in dengue endemic countries: a serious health concern. J Med Virol. 2020 Jul 7;

12. Ridwan R. COVID-19 and dengue: a deadly duo. Trop Doct. 2020 Jun 26;49475520936874.

13. Wee LE, Cherng BPZ, Conceicao EP, Goh KC-M, Wan WY, Ko KKK, et al. Experience of a Tertiary Hospital in Singapore with Management of a Dual Outbreak of COVID-19 and Dengue. Am J Trop Med Hyg. 2020 Sep 28;

14. Masyeni S, Santoso MS, Widyaningsih PD, Wedha Asmara DG, Nainu F, Harapan H, et al. Serological cross-reaction and co-infection of dengue and COVID-19 in Asia: Experience from Indonesia. Int J Infect Dis. 2020 Oct 25;

15. Verduyn M, Allou N, Gazaille V, Andre M, Desroche T, Jaffar M-C, et al. Co-infection of dengue and COVID-19: A case report. PLoS Negl Trop Dis. 2020 Aug 3;14(8):e0008476. 
16. Estofolete CF, Machado LF, Zini N, Luckemeyer GD, Moraes MM, Dos Santos TNIL, et al. Fatal stroke as presentation of SARS-CoV-2 and dengue virus coinfection. J Med Virol. 2020 Sep 3;

17. Bicudo N, Bicudo E, Costa JD, Castro JALP, Barra GB. Co-infection of SARS-CoV-2 and dengue virus: a clinical challenge. Braz J Infect Dis. 2020 Aug 26;

18. Pontes RL, de Brito BB, da Silva FAF, Correia TML, Teixeira AF, Oliveira MV, et al. Coinfection by SARS-CoV-2 and dengue virus in a dual viral circulation setting. Travel Med Infect Dis. 2020 Aug 25;101862.

19. Seelig F, Bezerra H, Cameron M, Hii J, Hiscox A, Irish S, et al. The COVID-19 pandemic should not derail global vector control efforts. PLOS Neglected Tropical Diseases. 2020 Aug 31;14(8):e0008606.

20. Olive M-M, Baldet T, Devillers J, Fite J, Paty M-C, Paupy C, et al. The COVID-19 pandemic should not jeopardize dengue control. PLoS Negl Trop Dis. 2020 Sep;14(9):e0008716.

21. Oidtman RJ, Lai S, Huang Z, Yang J, Siraj AS, Reiner RC, et al. Inter-annual variation in seasonal dengue epidemics driven by multiple interacting factors in Guangzhou, China. Nat Commun. 2019 Mar 8;10(1):1148.

22. Brito AF, Machado LC, Siconelli MJL, Oidtman RJ, Fauver JR, Carvalho RD de O, et al. Lying in wait: the resurgence of dengue virus after the Zika epidemic in Brazil. medRxiv. 2020 Aug $11 ; 2020.08 .10 .20172247$.

23. Wearing HJ, Rohani P. Ecological and immunological determinants of dengue epidemics. PNAS. 2006 Aug 1;103(31):11802-7.

24. Stoddard ST, Forshey BM, Morrison AC, Paz-Soldan VA, Vazquez-Prokopec GM, Astete H, et al. House-to-house human movement drives dengue virus transmission. Proceedings of the National Academy of Sciences. 2013;110(3):994-999.

25. Bosch QA ten, Singh BK, Hassan MRA, Chadee DD, Michael E. The Role of Serotype Interactions and Seasonality in Dengue Model Selection and Control: Insights from a Pattern Matching Approach. PLOS Neglected Tropical Diseases. 2016 May 9;10(5):e0004680.

26. Reiner RC, Stoddard ST, Forshey BM, King AA, Ellis AM, Lloyd AL, et al. Time-varying, serotype-specific force of infection of dengue virus. Proc Natl Acad Sci USA. 2014 Jul 1;111(26):E2694-2702.

27. Perkins TA, Reiner RC, España G, Ten Bosch QA, Verma A, Liebman KA, et al. An agent-based model of dengue virus transmission shows how uncertainty about breakthrough infections influences vaccination impact projections. PLoS Comput Biol. 2019 Mar 20;15(3):e1006710.

28. Cavany SM, España G, Lloyd AL, Waller LA, Kitron U, Astete H, et al. Optimizing the deployment of ultra-low volume and targeted indoor residual spraying for dengue outbreak response. PLOS Computational Biology. 2020 Apr 20;16(4):e1007743.

29. España G, Yao Y, Anderson KB, Fitzpatrick MC, Smith DL, Morrison AC, et al. Model-based assessment of public health impact and cost-effectiveness of dengue vaccination following screening for prior exposure. PLoS Negl Trop Dis. 2019 Jul 1;13(7):e0007482.

30. Morrison AC, Gray K, Getis A, Astete H, Sihuincha M, Focks D, et al. Temporal and Geographic Patterns of Aedes aegypti (Diptera: Culicidae) Production in Iquitos, Peru. J Med Entomol. 2004 Nov 1;41(6):1123-42.

31. Reiner RC, Stoddard ST, Scott TW. Socially structured human movement shapes dengue 
transmission despite the diffusive effect of mosquito dispersal. Epidemics. 2014 Mar;6:30-6.

32. Fraser B. COVID-19 strains remote regions of Peru. The Lancet. 2020 May 30;395(10238):1684.

33. Torres K, Alava F, Soto-Calle V, Llanos-Cuentas A, Rodriguez H, Llacsahuanga L, et al. Malaria Situation in the Peruvian Amazon during the COVID-19 Pandemic. The American Journal of Tropical Medicine and Hygiene. 2020 Nov 4;103(5):1773-6.

34. Chafloque-Vásquez RA, Pampa-Espinoza L, Celis Salinas JC. Seroprevalencia de COVID-19 en trabajadores de un hospital de la Amazonía peruana. Acta Med Peru [Internet]. 2020 Sep 1 [cited 2020 Nov 16];37(3). Available from: https://amp.cmp.org.pe/index.php/AMP/article/view/1050

35. Nacher M, Douine M, Gaillet M, Flamand C, Rousset D, Rousseau C, et al. Simultaneous dengue and COVID-19 epidemics: Difficult days ahead? PLOS Neglected Tropical Diseases. 2020 Aug 14;14(8):e0008426.

36. Huang E. Outbreak of dengue fever in Southeast Asia is "exploding” amid the coronavirus fight [Internet]. CNBC. 2020 [cited 2020 Jul 16]. Available from:

https://www.cnbc.com/2020/07/10/outbreak-of-dengue-fever-in-southeast-asia-is-explodingamid-the-coronavirus-fight.html

37. Dantés HG, Manrique-Saide P, Vazquez-Prokopec G, Morales FC, Siqueira Junior JB, Pimenta F, et al. Prevention and control of Aedes transmitted infections in the post-pandemic scenario of COVID-19: challenges and opportunities for the region of the Americas. Memórias do Instituto Oswaldo Cruz [Internet]. 2020 Aug 5 [cited 2020 Aug 24];115. Available from: http://www.scielo.br/scielo.php?script=sci_abstract\&pid=S007402762020000100851\&lng=en\&nrm=iso\&tlng=en

38. Lim JT, Dickens BSL, Chew LZX, Choo ELW, Koo JR, Aik J, et al. Impact of sars-cov-2 interventions on dengue transmission. PLOS Neglected Tropical Diseases. 2020 Oct 29;14(10):e0008719.

39. Parra B, Rengifo G, Méndez F, Burbano ME, Arias JF, Muñoz J, et al. HUMAN AND MOSQUITO INFECTIONS BY DENGUE VIRUSES DURING AND AFTER EPIDEMICS IN A DENGUE-ENDEMIC REGION OF COLOMBIA. The American Journal of Tropical Medicine and Hygiene. 2006 Apr 1;74(4):678-83.

40. Ratanawong P, Kittayapong P, Olanratmanee P, Wilder-Smith A, Byass P, Tozan Y, et al. Spatial Variations in Dengue Transmission in Schools in Thailand. PLOS ONE. 2016 Sep 26;11(9):e0161895.

41. Sujariyakul A, Prateepko S, Chongsuvivatwong V, Thammapalo S. Transmission of Dengue Haemorrhagic Fever: At Home or School? 2005;29:9.

42. Waterman SH, Novak RJ, Sather GE, Bailey RE, Rios I, Gubler DJ. Dengue Transmission in Two Puerto Rican Communities in 1982. The American Journal of Tropical Medicine and Hygiene. 1985 May 1;34(3):625-32.

43. Koopman JS, Prevots DR, Mann MAV, Dantes HG, Aquino MLZ, Longini IM, et al. Determinants and Predictors of Dengue Infection in Mexico. Am J Epidemiol. 1991 Jun 1;133(11):1168-78.

44. Ko Y-C, Chen M-J, Yeh S-M. The Predisposing and Protective Factors against Dengue Virus Transmission by Mosquito Vector. American Journal of Epidemiology. 1992 Jul 15;136(2):21420. 
medRxiv preprint doi: https://doi.org/10.1101/2020.11.17.20210211; this version posted November $18,2020$. The copyright holder for this

It is made available under a CC-BY 4.0 International license.

45. Anders KL, Nga LH, Thuy NTV, Ngoc TV, Tam CT, Tai LTH, et al. Households as Foci for Dengue Transmission in Highly Urban Vietnam. PLOS Neglected Tropical Diseases. 2015 Feb 13;9(2):e0003528.

46. McBride WJH, Mullner H, Muller R, Labrooy J, Wronski I. Determinants of Dengue 2 Infection among Residents of Charters Towers, Queensland, Australia. American Journal of Epidemiology. 1998 Dec 1;148(11):1111-6.

47. Olsen SJ. Decreased Influenza Activity During the COVID-19 Pandemic — United States, Australia, Chile, and South Africa, 2020. MMWR Morb Mortal Wkly Rep [Internet]. 2020 Sep 18 [cited 2020 Sep 21];69. Available from: https://www.cdc.gov/mmwr/volumes/69/wr/mm6937a6.htm

48. Sherrard-Smith E, Hogan AB, Hamlet A, Watson OJ, Whittaker C, Winskill P, et al. The potential public health consequences of COVID-19 on malaria in Africa. Nature Medicine. 2020 Aug 7;16.

49. Weiss DJ, Bertozzi-Villa A, Rumisha SF, Amratia P, Arambepola R, Battle KE, et al. Indirect effects of the COVID-19 pandemic on malaria intervention coverage, morbidity, and mortality in Africa: a geospatial modelling analysis. The Lancet Infectious Diseases [Internet]. 2020 Sep 21 [cited 2020 Sep 22];0(0). Available from: https://www.thelancet.com/journals/laninf/article/PIIS1473-3099(20)30700-3/abstract

50. Abbas K, Procter SR, van Zandvoort K, Clark A, Funk S, Mengistu T, et al. Routine childhood immunisation during the COVID-19 pandemic in Africa: a benefit-risk analysis of health benefits versus excess risk of SARS-CoV-2 infection. The Lancet Global Health. 2020;8(10):e1264-72.

51. Jenness SM, Guillou AL, Chandra C, Mann LM, Sanchez T, Westreich D, et al. Projected HIV and Bacterial STI Incidence Following COVID-Related Sexual Distancing and Clinical Service Interruption. medRxiv. 2020 Sep 30;2020.09.30.20204529.

52. Dzib-Florez S, Ponce-García G, Medina-Barreiro A, González-Olvera G, Contreras-Perera Y, Castillo-Centeno FD, et al. Evaluating Over-the-Counter Household Insecticide Aerosols for Rapid Vector Control of Pyrethroid-Resistant Aedes aegypti. 2020 Aug 3;tpmd200515.

53. Double trouble: South Asia braces for dengue outbreak amid coronavirus pandemic [Internet]. 2020 [cited 2020 Sep 24]. Available from: https://news.cgtn.com/news/2020-06-18/South-Asiabraces-for-Dengue-outbreak-amid-coronavirus-pandemic--Rq4C2WCMMM/index.html

54. Horton R. Offline: COVID-19 is not a pandemic. The Lancet. 2020 Sep 26;396(10255):874.

55. España G, Hogea C, Guignard A, Ten Bosch QA, Morrison AC, Smith DL, et al. Biased efficacy estimates in phase-III dengue vaccine trials due to heterogeneous exposure and differential detectability of primary infections across trial arms. PLoS ONE. 2019;14(1):e0210041.

56. Perkins TA, Garcia AJ, Paz-Soldán VA, Stoddard ST, Reiner RC, Vazquez-Prokopec G, et al. Theory and data for simulating fine-scale human movement in an urban environment. J R Soc Interface [Internet]. 2014 Oct 6 [cited 2018 Oct 5];11(99). Available from:

https://www.ncbi.nlm.nih.gov/pmc/articles/PMC4233749/

57. Reiner RC, Stoddard ST, Vazquez-Prokopec GM, Astete H, Perkins TA, Sihuincha M, et al. Estimating the impact of city-wide Aedes aegypti population control: An observational study in Iquitos, Peru. PLoS Negl Trop Dis. 2019 May;13(5):e0007255. 
medRxiv preprint doi: https://doi.org/10.1101/2020.11.17.20210211; this version posted November 18, 2020. The copyright holder for this preprint (which was not certified by peer review) is the author/funder, who has granted medRxiv a license to display the preprint in perpetuity. It is made available under a CC-BY 4.0 International license .

Aedes aegypti control by indoor Ultra Low Volume (ULV) insecticide spraying in Iquitos, Peru. Barrera R, editor. PLOS Neglected Tropical Diseases. 2018 Apr 6;12(4):e0006378.

59. Lee J-S, Filatova T, Ligmann-Zielinska A, Hassani-Mahmooei B, Stonedahl F, Lorscheid I, et al. The Complexities of Agent-Based Modeling Output Analysis. JASSS. 2015;18(4):4.

60. R Core Team. R: A Language and Environment for Statistical Computing. R Foundation for Statistical Computing; 2018.

61. Wood S. mgcv: Mixed GAM Computation Vehicle with Automatic Smoothness Estimation [Internet]. 2020 [cited 2020 Sep 25]. Available from: https://CRAN.R-project.org/package=mgcv 